Revue scientifique sur la conception et l'aménagement de l'espace

\title{
Los conflictos de escalas para valorar la apropiación urbano-rural sustentable en el valle de México
}

Conflits d'échelles pour valoriser l'appropriation urbano-rurale durable dans la vallée de Mexico

Conflicts of scales to assess the sustainable urban-rural appropriation in the valley of Mexico

\section{Hermilio Navarro, Ma Antonia Pérez y Diego Flores}

\section{(2) OpenEdition}

\section{Journals}

Edición electrónica

URL: http://journals.openedition.org/paysage/15019

DOI: 10.4000/paysage.15019

ISSN: 1969-6124

\section{Editor.}

École nationale supérieure du paysage de Versailles-Marseille, Institut national des sciences appliquées Centre Val de Loire - École de la nature et du paysage, École nationale supérieure d'architecture et de paysage de Bordeaux, École nationale supérieure d'architecture et de paysage de Lille, Agrocampus Angers

\section{Referencia electrónica}

Hermilio Navarro, Ma Antonia Pérez et Diego Flores, « Los conflictos de escalas para valorar la apropiación urbano-rural sustentable en el valle de México », Projets de paysage [En ligne], 8 | 2012, mis en ligne le 13 juillet 2012, consulté le 11 mars 2021. URL : http://journals.openedition.org/paysage/ 15019 ; DOI : https://doi.org/10.4000/paysage.15019 


\title{
Los conflictos de escalas para valorar la apropiación urbano-rural sustentable en el valle de México
}

\author{
Conflits d'échelles pour valoriser l'appropriation urbano-rurale durable dans la \\ vallée de Mexico \\ Conflicts of scales to assess the sustainable urban-rural appropriation in the \\ valley of Mexico
}

Hermilio Navarro, Ma Antonia Pérez y Diego Flores

1 La investigación contempla aportar información y apreciaciones diversas, que ilustran y documentan los límites y, en su caso el fracaso y posibles alternativas, de un estilo de urbanización limitada de una gran aglomeración metropolitana como es el Valle de México. Al respecto, se reconoce que los mecanismos en que se ha basado la periurbanización no solo ha consumido excesivo espacio, sino que ha determinado fuertemente la desorganización de los territorios periurbanos. También, se ha privilegiado la información relativa a la dinámica de una modalidad de crecimiento urbano interminable, la consecuente concurrencia sobre los territorios "siempre circundantes" cada vez más distantes, al interior de los cuales sus poblaciones rurales y periurbanas, sus patrimonios y sin duda sus tierras agrícolas son subordinados a las necesidades y reglas del sistema urbano. Además, de manera importante se evidencia y registra la expropiación de las aguas superficiales y de numerosos acuíferos, al interior de la misma cuenca metropolitana, así como de cuencas vecinas; iniciativas que son asociadas a los consecuentes efectos económicos, sociales y ambientales en las agriculturas.

2 Los procesos y hechos registrados tienden a evidenciar la falta de un proyecto de planificación urbana integral a corto y medio plazo, así como la emergencia de riesgos entrópicos evidenciados por el disfuncionamiento y perdida de durabilidad de las agriculturas periurbanas, incluso del riesgo de viabilidad del sistema urbano-rural en su conjunto. 
Las transformaciones de la población urbano-rural muestran los últimos 60 años una disminución relativa de la población rural en relación a la población urbana, así como un incremento en números absolutos de la población rural. Lo anterior considerando que el año de 1950 la población rural representaba el $57.3 \%$ de la población total, el año 1970 el $41.2 \%$, el año 1990 el $28.6 \%$ y el año 2010 el $22.4 \%$. En 1950 la población rural registró 4.8 millones de habitantes, en 1980 fueron 22.55 millones, con un incremento del $52.4 \%$, y 24.42 millones en 2010 (figura 1).

Figura 1. La dinámica de la población rural y urbana en México

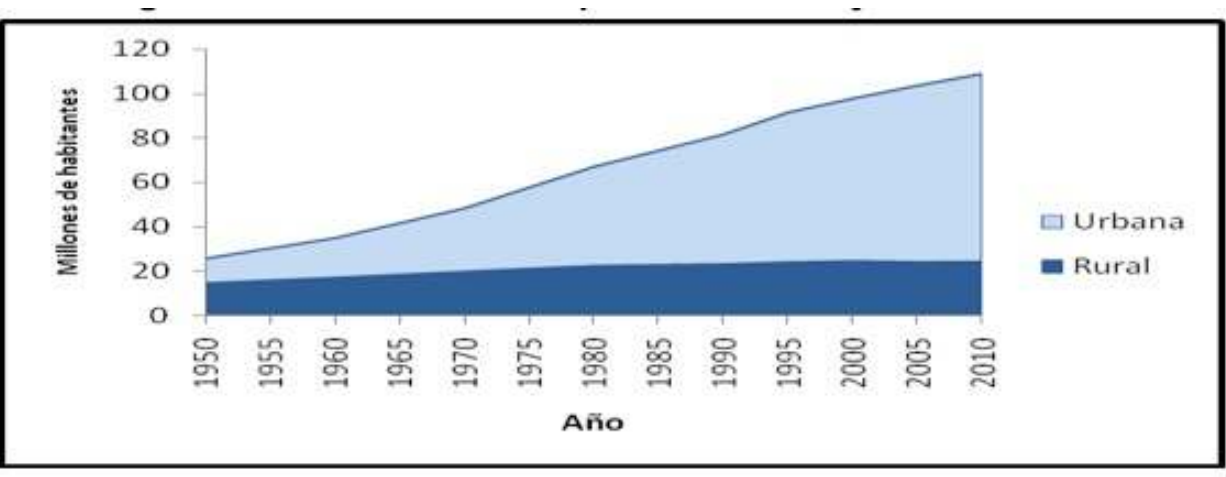

Fuente : elaboración propia con base en INEGI.

El trabajo de SEDESOL-CONAPO-INEGI (2007), documenta datos de transformaciones en 3 zonas metropolitanas vecinas, ubicadas en el centro de México, las cuales son: Valle de México, Puebla-Tlaxcala y Toluca (ZMC) ${ }^{1}$. En complemento se amplia y profundiza el análisis de cambios en la zona metropolitana del Valle de México (ZMVM), con la finalidad de ilustrar las limitaciones del llamado proceso de urbanización, en particular las insuficiencias del proceso de planificación para desarrollo urbano, entre las cuales las carencias servicios típicamente urbanos, por ejemplo, aprovisionamiento de agua en cantidad y calidad, la incapacidad de gestión pública y de los actores para la conservación de espacios verdes abiertos periurbanos - entre ellos los territorios agropecuarios -, las insuficiencias de programas de gestión ambiental, la insuficiencia y creciente carencia de redes viales, de alumbrado, de tratamiento de aguas residuales y drenaje, de servicios paisajísticos, otros.

\section{Las metrópolis del centro de México}

El territorio de las ZMC se localiza al sur del trópico de cáncer, en la provincia fisiográfica Eje Neovolcánico Transversal (ENT). En estas metrópolis existen climas templados, en alturas de 2000 a 2700 m, y una gran concentración ecosistémica original de lagos, lagunas y numerosos volcanes (Demant, 1978).

El paisaje de figura 2, desde el oeste de ZM Puebla-Tlaxcala, muestra los volcanes Popocatepetl e Iztacihuatl, los cuales se encuentran en frontera con la vecina ZMVM, situada al poniente. 
Figura 2. La Sierra Nevada y los volcanes Popocatepetl e Iztacihuatl

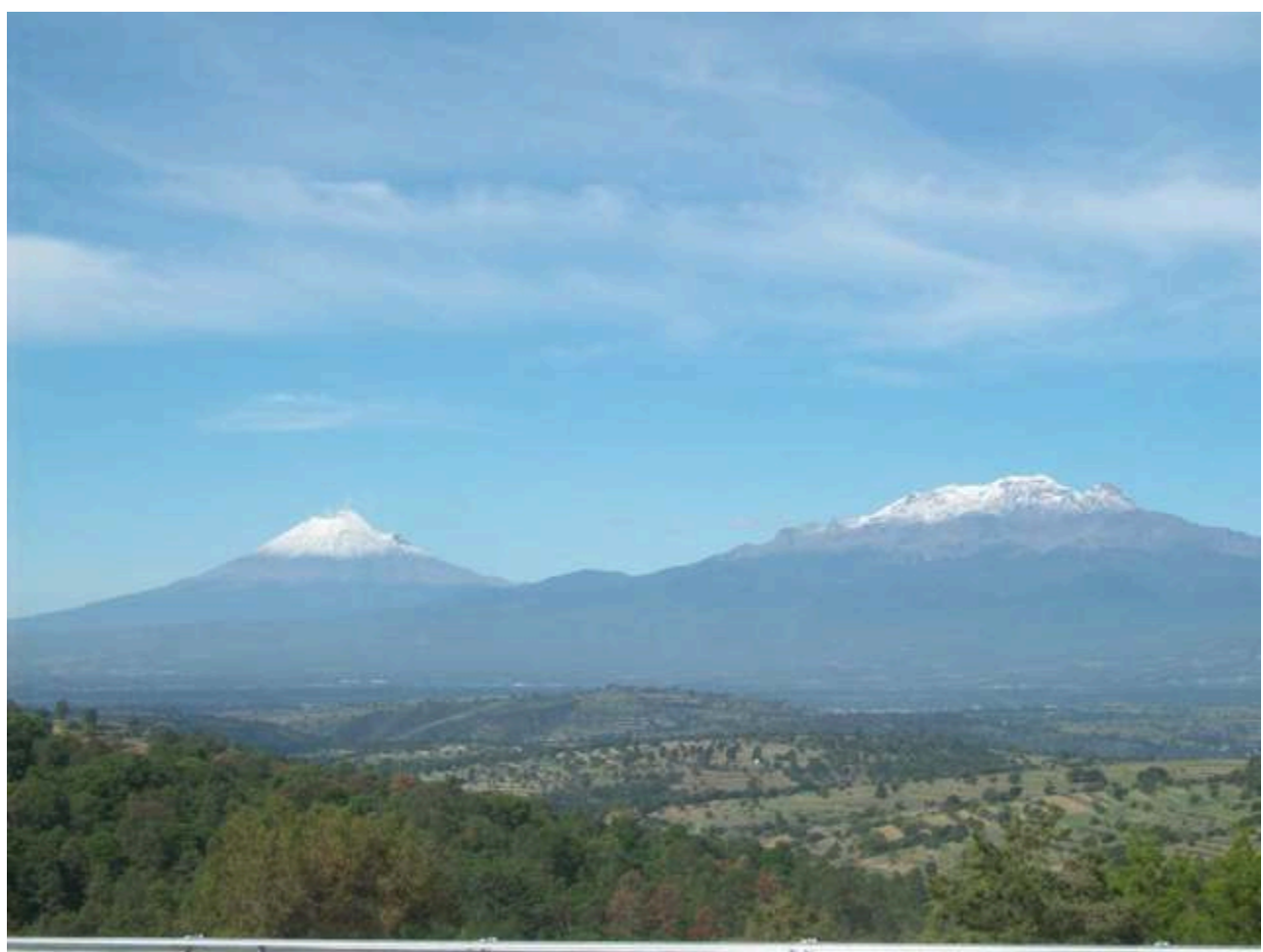

Fuente : Hermilio Navarro (2008)

7 Según SEDESOL-CONAPO-INEGI (2007) ${ }^{2}$ el crecimiento espacial de varias ciudades de México sobre el territorio de dos o más municipios o estados, ha permitido desde 1940 la formación y crecimiento de 56 Zonas Metropolitanas (ZM). Sin embargo, se diagnostican como factores limitantes de los procesos de urbanización ocurridos :

1. la falta de acuerdos,

2. las diferencias en la normatividad urbana,

3. las disposiciones administrativas contrapuestas y

4. la ausencia de mecanismos eficaces de coordinación intersectorial e intergubernamental.

El estudio concluye que estos 4 factores son obstáculos para el adecuado funcionamiento y desarrollo de las metrópolis, en particular para: la planeación y regulación de su crecimiento físico, la provisión de servicios públicos y el cuidado de su entorno ambiental. Consideramos que debido a la incapacidad de gobernanza territorial a escala metropolitana, es decir que la urbanización sobre otros estados (o Departamentos) y municipios vecinos, conllevó a la confrontación jerárquica entre diferentes autoridades territoriales; debido a que en cada escala territorial sus autoridades desempeñan cargos de elección mediante voto directo y compromisos asociados. Por ejemplo el regente de la ciudad-capital, los gobernadores de estados y más de 100 presidentes municipales, cada uno bajo dinámicas y procesos espacio-temporales diferentes.

9 Por tanto, es comprensible la dificultad en escala temporal para conciliar intereses comunes y definir proyectos de urbanización con la misma visión y compromiso. Además, el mapa espacial de ZMC registra un entramado complejo de actores políticos de diferentes partidos, muchas veces en conflicto, así como diferentes actores económicos. 
10 Las ZMC registran una importante concentración de la población nacional, así como el registro de tasas importantes de crecimiento medio anual, entre el periodo 1990 al 2005.

Cuadro 1. Población total, tasa de crecimiento, superficie y densidad media urbana en ZMC, 1990-2005

\begin{tabular}{|c|c|c|c|c|c|c|c|c|}
\hline \multirow{3}{*}{$\begin{array}{c}\text { Zonas } \\
\text { metropolitanas } \\
\text { Valle de México }\end{array}$} & \multicolumn{4}{|c|}{ Población total en diferentes años (miles) } & \multirow{2}{*}{\multicolumn{3}{|c|}{$\begin{array}{c}\text { Tasa de } \\
\text { crecimiento } \\
\text { medio anual } \\
(\%)\end{array}$}} & \multirow{3}{*}{$\begin{array}{c}\text { Superfi- } \\
\text { cie } \\
\left(\mathrm{km}^{2}\right)\end{array}$} \\
\hline & \multirow{2}{*}{$\begin{array}{c}1990 \\
15^{\prime} 563.8\end{array}$} & \multirow{2}{*}{$\begin{array}{c}1995 \\
17^{\prime} 297.5\end{array}$} & \multirow{2}{*}{$\begin{array}{c}2000 \\
18^{\prime} 396.7\end{array}$} & \multirow{2}{*}{$\begin{array}{c}2005 \\
19^{\prime} 239.9\end{array}$} & & & & \\
\hline & & & & & 1.9 & 1.5 & 0.8 & \\
\hline $\begin{array}{l}\text { Puebla- } \\
\text { Tlaxcala }\end{array}$ & $1 ' 735.7$ & $2^{\prime} 016.8$ & $2 ' 220.5$ & $2 ' 470.2$ & 2.7 & 2.3 & 1.9 & 2,223 \\
\hline Toluca, México & $1^{\prime} 061.1$ & 1'272.3 & $1 ' 471.2$ & $1 ' 633.1$ & 3.3 & 3.5 & 1.9 & 2,038 \\
\hline $\begin{array}{c}\text { Total Zonas } \\
\text { Metropolitanas }\end{array}$ & $18 ' 360.6$ & $20 ’ 586.6$ & $22 ' 088.4$ & 23'343.2 & I & I & I & 12,115 \\
\hline
\end{tabular}

Fuente : con base en SEDESOL-CONAPO-INEGI (2007).

Las ZMC registraron 18.36 millones en 1990, 20.58 en 1995, 22.08 el año 2000 y 23.34 en 2005. Las tasas de crecimiento fueron de1.9 a $3.3 \%$ en 1990-95, las cuales disminuyeron en 2000-05 (Cuadro 1). La superficie de ZMC suma 12,115 mil km²

La contribución de las ZMC en el Producto Interno Bruto (PIB) es $31.7 \%$ del PIB nacional ; del cual la ZMVM y ZM Toluca aportan el $27.5 \%$ (INEGI, 2011). Sin embargo, el crecimiento poblacional en las 4 últimas décadas y la acelerada expansión espacial del mismo, han ocasionado importantes problemas y conflictos, asociados a la concurrencia de intereses entre los diferentes actores públicos y privados por los recursos territoriales. Sin duda, un crecimiento desordenado sobre los espacios circundantes siempre presentes, sean estos los territorios periurbanos funcionalizados por la irrupción del sistema metropolitano.

Hasta la fecha, los hechos evidencian severas implicaciones y efectos en los sistemas estatales y municipios, en sus recursos tierra, agua, bosques y sus diversas agriculturas y agroecosistemas. Expansión espacial bajo una multiplicidad de circunstancias sociales y locales, asociadas a impactos y riesgos para la viabilidad de sus territorios y recursos patrimoniales

14 Según Benítez et. al., (2004), en la ZM Puebla-Tlaxcala en los últimos quince años destacó la emergencia de escenarios conflictivos: extracción de agua del municipio (mpio) Nealtican, expropiación de terrenos ejidales a campesinos del mpio Cholula, la disputa de límites territoriales entre Cholula y Puebla, la instalación de depósitos de desechos en mpio Tecali, el desalojo de aguas residuales en mpio Atlixco, los asentamientos masivos e irregulares de colonias marginales de Puebla los últimos veinte años. Los resultados evidencian los conflictos entre la capital de la ZM y sus mpios periurbanos. En la ZM Puebla-Tlaxcala, según Morales $(2005)^{3}$, la sobreexplotación de los acuíferos, la deforestación y creciente erosión, apresuran el exterminio de los manantiales, debido a la falta de gestión de los recursos hídricos y la falta de compromiso y observancia de la ley por las autoridades locales

En ZMVM, Rivera-Vázquez et al., (2007), señalan que en los ríos Texcoco, Chapingo y Bernardino, las cantidades de coliformes totales (número más probable, NMP) varió de $1.6 \times 10^{4}$ a $2.4 \times 10^{7} \mathrm{NMP} 100 \mathrm{~mL}^{-1}$; de coliformes fecales varió de $1 \times 10^{4}$ a $2.4 \times 10^{7}$; y los 
huevos de helmintos de 0.38 a 6.78 huevos $\mathrm{L}^{-1}$. Estas cantidades rebasan los límites permisibles establecidos por la norma NOM-001-SEMARNAT, y se recomienda urgente el tratamiento de esta agua. La calidad insuficiente del agua plantea riesgos generalizados en la salud, debido a su utilización en riego de cultivos agrícolas, su infiltración al acuífero y su contaminación.

La figura 3 ilustra la disponibilidad de aguas residuales tratadas mediante un sistema de tubería a nivel parcelario (boca toma en rojo), así como de aguas residuales sin tratar (canal en parte inferior de la boca toma), las cuales se mezclan para ser aplicadas directamente al riego parcelario.

Figura 3. Disponibilidad de aguas residuales tratadas y sin tratamiento para uso agropecuario, Mixquic, ZMVM

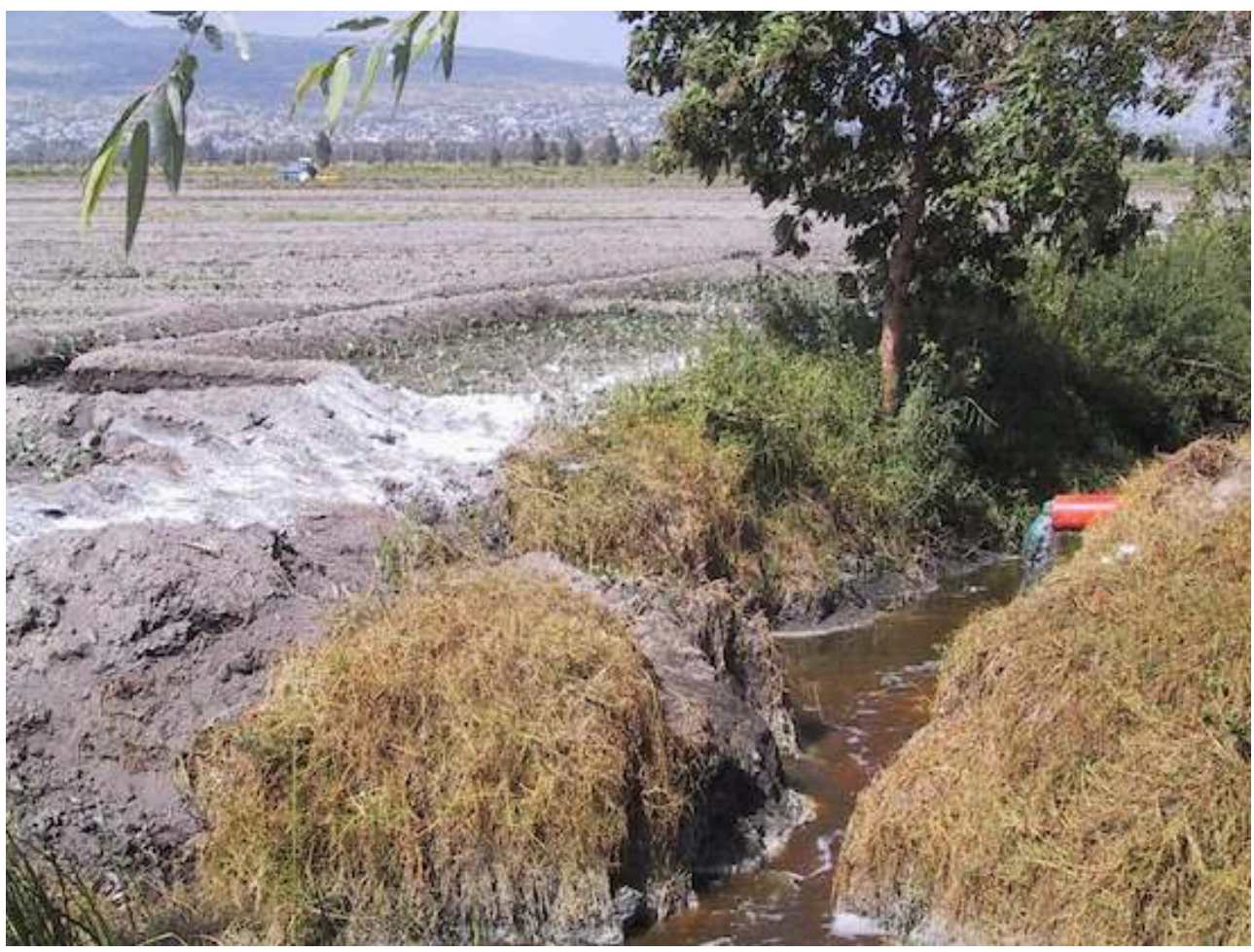

Fuente : Hermilio Navarro (2008)

17 En el este del valle de México, Navarro y Pérez et al, (2005) al evaluar la periódicamente y durante 3 años la contaminación del río Texcoco, ocasionada por los drenajes de los poblados, diagnosticaron contaminación química y biológica, al interior de las cuales algunos parámetros se diagnosticaron en niveles superiores a los establecidos por las normas

\section{Dinámicas y conflictos en ZMVM}

En la ZMVM existía hasta mediados del siglo XVI la ciudad capital llamada Tenochitlan, localizada al interior de una cuenca endorreica y prácticamente en medio de un conjunto de lagos que cubrían sensiblemente un mil $\mathrm{km}^{2}$, según figura 5 . Entre una diversidad de poblados, al sur del sistema lagunario se identifican Xochimilco, Milpa 
Alta y Mixquic; al este Texcoco y Tepexpan y al norte Zumpango y Xaltocan. Estos últimos 4 poblados hoy forman parte del estado de México y de la ZMVM (figura 4).

Figura 4. Esquema del sistema lagunario del valle de México durante el siglo XVI

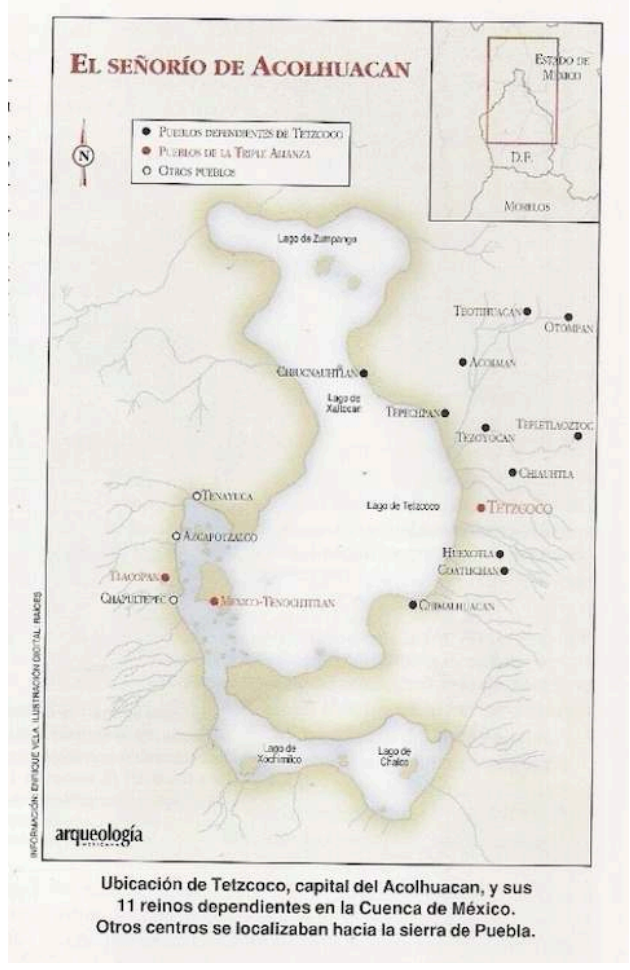

Fuente : revista Arqueología, México.

En figura 5 se ilustra la construcción, función y paisaje del sistema de producción agrícola creado en "islas artificiales" a orillas del sistema lagunario, el cual es conocido hoy como chinampa. Un sistema basado en el manejo de la gran biodiversidad mesoamericana en conectividad ecosistemica con numerosas poblaciones vegetales y animales que han sido introducidas; en si un complejo sistema territorial con muy diversos tipos de intensificación de los sistemas agrícolas (barbecho y descanso, de temporal en laderas, de humedad y las chinampas en las planicies), en combinación con prácticas de caza y pesca asociada a los lagos y su entorno. 
Figura 5. llustración de una chinampa recién construida (a) y vista de chinampas con invernaderos para producción de hortalizas (b)
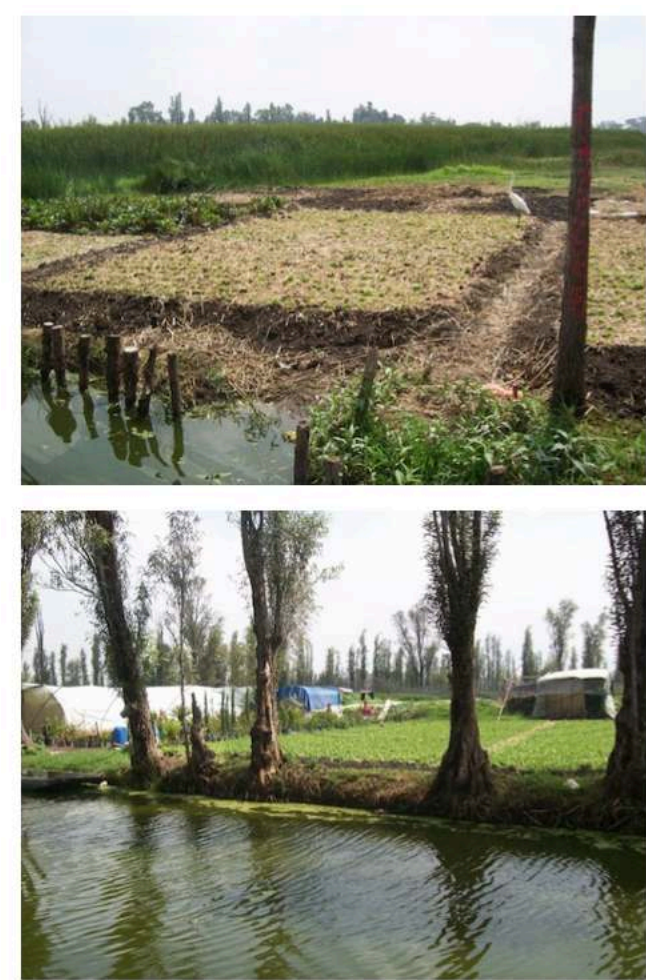

Fuente : museo Antropología e Historia, México y Navarro (2004).

Sin embargo, con el crecimiento de la ciudad de México se reportan nuevos problemas para abastecimiento de agua, en consecuencia nuevas necesidades y por tanto, los conflictos que se generan por los proyectos realizados para su satisfacción. Desde inicios del siglo XX se registra la construcción de una acueducto en el sur de la ZMVM, con el objetivo de aprovechar el agua superficial disponible en la gran región chinampera de Xochimilco-Miquic, para la cual se estimaba en la época un territorio con una superficie agrícola de $12 \mathrm{mil} \mathrm{ha,} \mathrm{con} \mathrm{manejo} \mathrm{agrícola} \mathrm{bajo} \mathrm{el} \mathrm{sistema} \mathrm{de}$ chinampa con su importante legado patrimonial indígena-campesino. En consecuencia, con impactos importantes de fragilización de la agricultura y su despatrimonialización (Navarro, 2004) (figura 6). 
Figura 6. Acueducto Xochimilco-Mixquic para agua a la ciudad de México - 1914

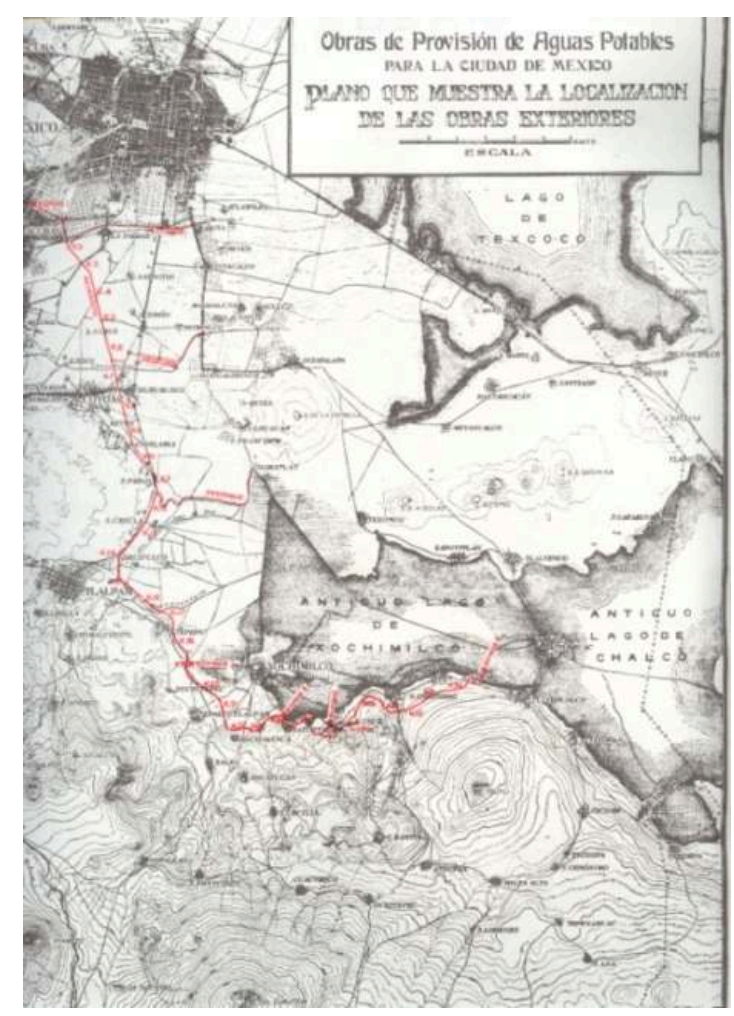

Fuente : Anexo de pyto técnico, Sistema drenaje profundo de ciudad de México (1984).

21 El crecimiento permanente de necesidades de agua para la ciudad de México, durante los años fue acompañado también de iniciativas para aprovisionarse de aguas subterráneas provenientes de diversos acuíferos de la ZMVM, los cuales se localizaban cada vez en territorios más distantes. Esta modalidad se ha amplificado y combinado, manteniéndose hasta la fecha, con diversos programas que han decretado de interés público el aprovisionamiento de agua para la ZMVM, en consecuencia apropiándose de los inventarios existentes en los valles y acuíferos de las cuencas vecinas, también cada vez más lejanas (Comisión Nacional del Agua, 1994).

El crecimiento espacial de la ZMVM ha sido dimensionado por diversos autores, entre ellos Covarrubias (2000) ha estimado una expansión que varía entre 6 a 8 veces del tamaño original, durante el periodo 1910-2000.

Para ilustrar los términos, en su caso excesos de la expansión territorial reciente, con base en cifras reportadas por el Gobierno del estado de México el año 2001, se identificaron los fraccionamientos y cuantificamos sus casas autorizadas y construidas durante el periodo 2008-10. Los resultados muestran en 10 municipios del norte la ZMV, las estimaciones siguientes : en 2008 29,603 casas, 2009 sumó 43,750 y 2010 30,019 casas. El total fue de 103,373 casas. Cabe subrayar que el municipio de Zumpango reconocido por la importancia de su economía, así como por su posicionamiento hasta hace pocos años como periurbano distante, durante dicho periodo de tres años totalizó 31,189 casas, equivalentes al $30.2 \%$.

En las imágenes de la figura 7, se muestra en el municipio de Zumpango el mercado de la venta de parcelas agrícolas aún con maíz (a), y en el boulevard principal la publicidad de las empresas inmobiliarias (b). 
Figura 7. Zumpango, edo México : venta de parcelas y publicidad de empresas inmobiliarias constructoras de viviendas
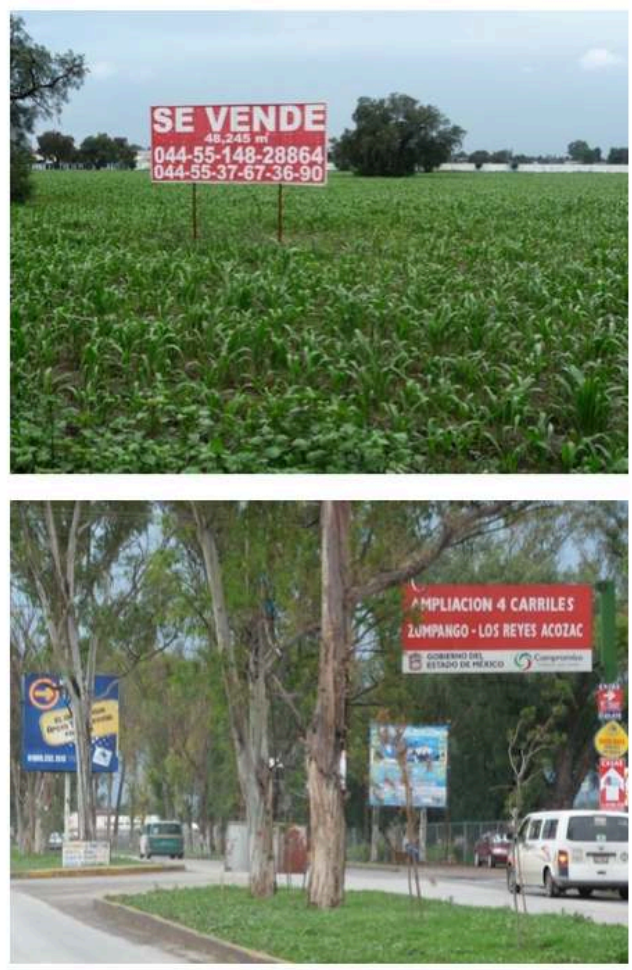

Fuente : Hermilio Navarro (2009) causalidad la omisión deliberada, y en su caso colusión por falta de programas efectivos de planificación, ejecución y seguimiento. En los territorios periurbanos abiertos, en particular los utilizados con diversos fines agropecuarios, es frecuente la emergencia de conflictos territoriales ocasionados por asentamientos irregulares imprevisibles, mediante los cuales se instalan numerosas familias, despojando por tanto a los propietarios originales de sus tierras, con los consecuentes conflictos entre uno y otros (figuras 8 a y b). En la ZMVM-área de la ciudad de México, se registran 
oficialmente por la Secretaria del Medio Ambiente, del Gobierno de la ciudad de México (2011), asentamientos irregulares en aproximadamente $10 \mathrm{mil} \mathrm{ha.}$

Figura 8. Ejemplo de problemática en ZMVM

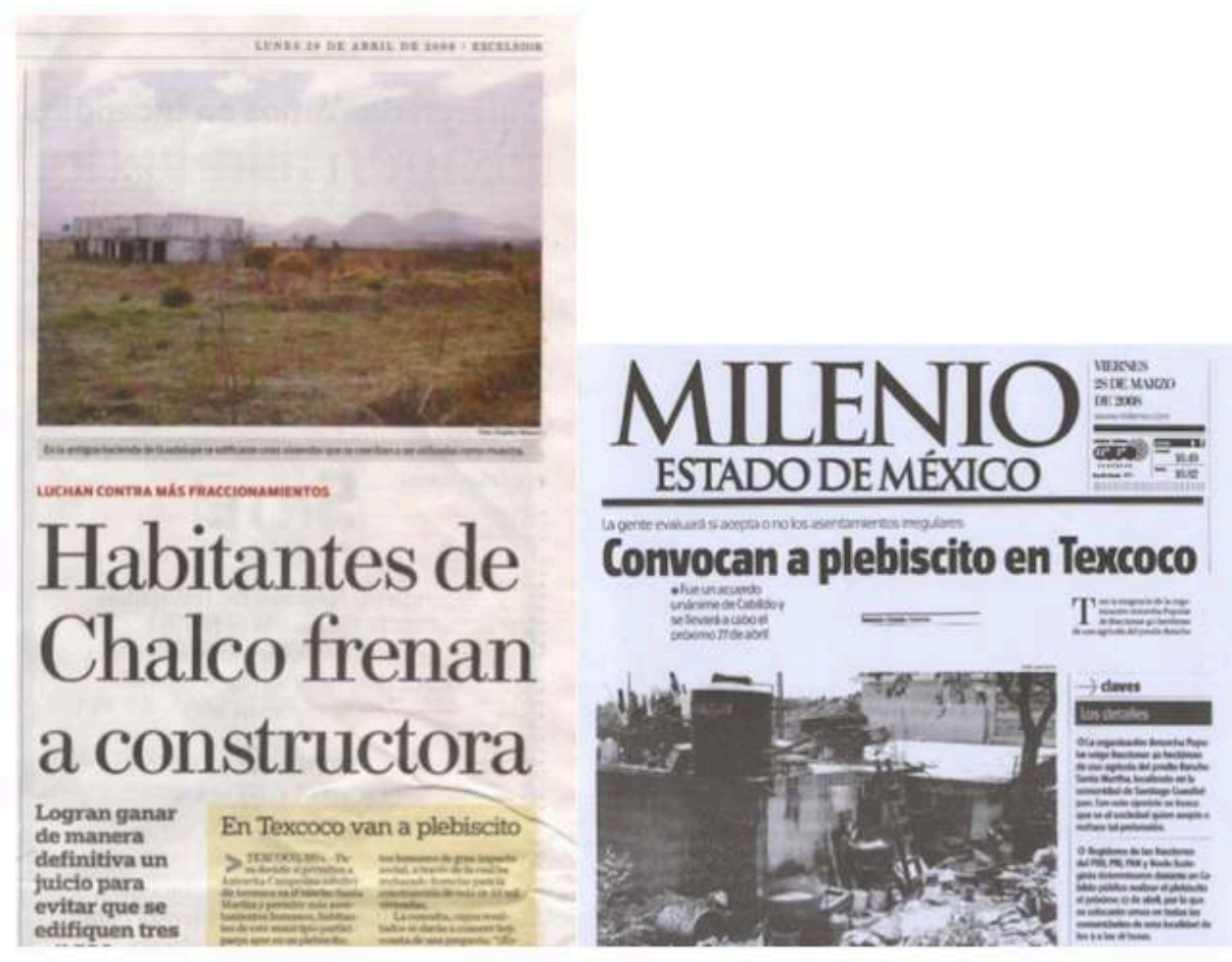

Manifestaciones frente a constructora inmobiliaria (a) y convocatoria de organizaciones ciudadanas para plebiscito en municipio Texcoco contra asentamientos irregulares (b)

Los asentamientos irregulares de la ZMVM típicamente se localizan en condiciones fisiográficas de difícil acceso, por tanto con fuertes limitaciones para la disponibilidad y beneficios de los servicios básicos de agua potable, electricidad, caminos, transporte y drenaje, entre otros (figura 9). 
Figura 9. Modalidad de asentamientos irregulares de ZMVM
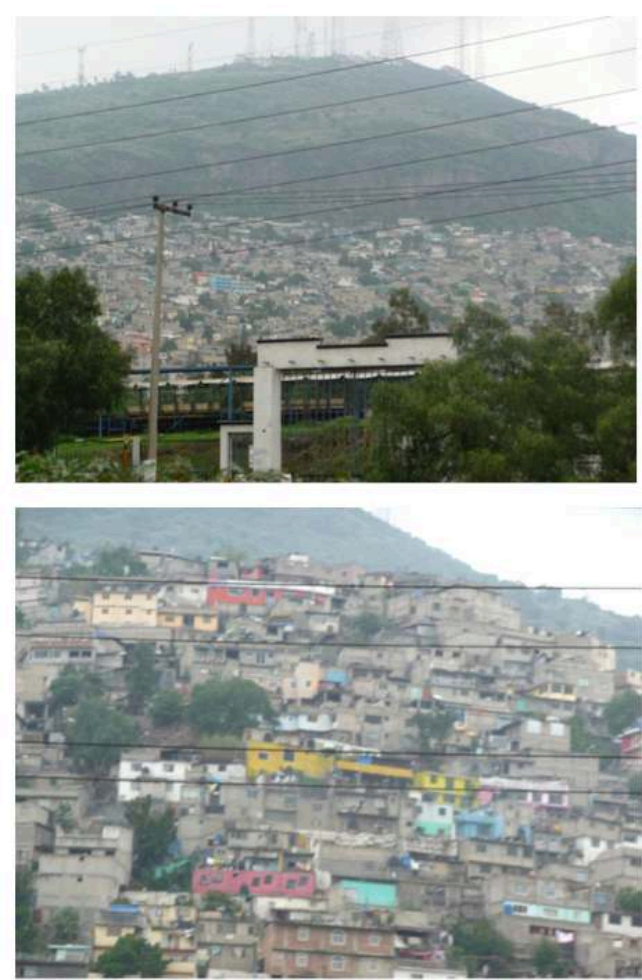

Fuente : Hermilio Navarro (2009)

29 Además de los conflictos originados por el modelo de crecimiento entrópico-urbano de la ZMVM, existen impactos muy diversos sobre los territorios agrícolas periurbanos y de las chinampas, los cuales sin duda afectan su multifuncionalidad y por tanto, los servicios eco sistémicos favorables y necesarios para la viabilidad de la ZMVM. Insistimos que desconocer y no fomentar, ni apoyar la intensificación de la multifuncionalidad actual y futura de los territorios agrícolas periurbanos, ha sido una estrategia desfavorable para la planificación del desarrollo social urbano-rural necesario. 
Figura 10. Sistema de canales y chinampas en economía local
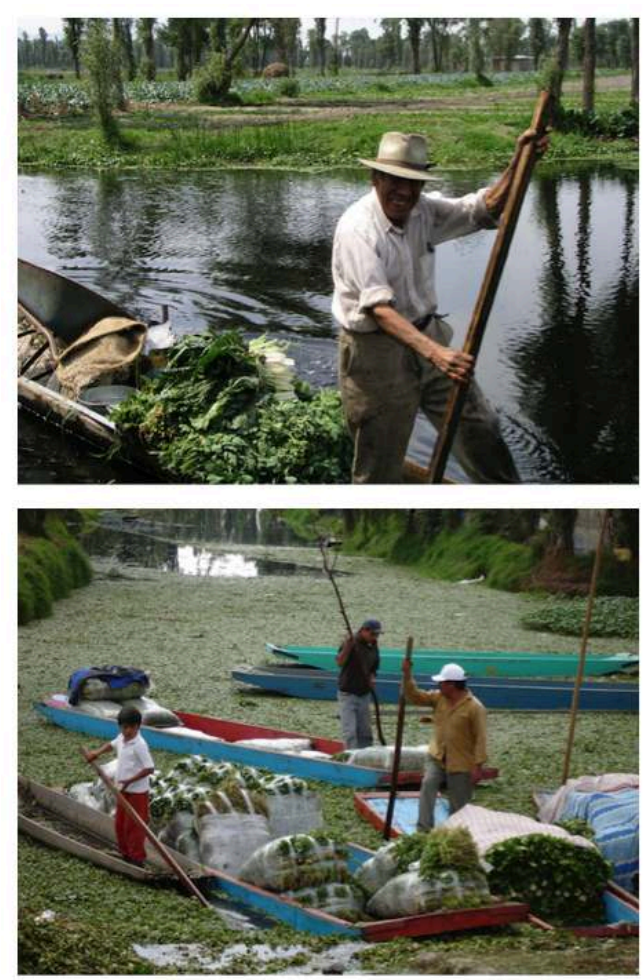

30 La economía agrícola chinampera permite al campesino obtener dos a tres cosechas por parcela/año; además de las diversas funciones territoriales que implican (Olivares, 2007) (figura 11). 
Figura 11. Etapa inicial y final de almacigo y trasplante en chinampa
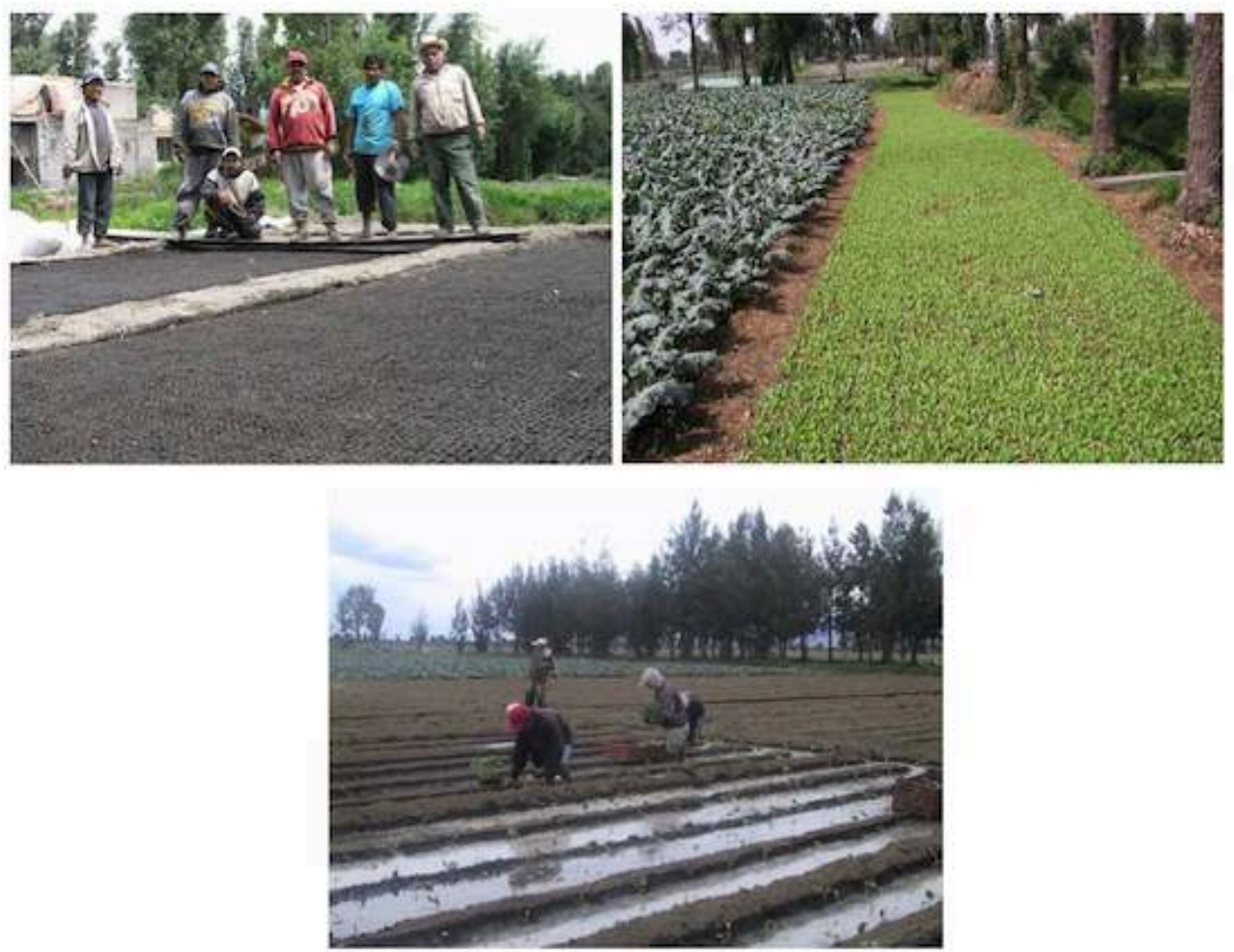

Fuente : Hermilio Navarro y Ma Pérez (2006).

31 La chinampa es una construcción social que reproduce la biodiversidad, la economía local, la configuración territorial, la re-apropiación patrimonial y genera paisaje (figura 12). 
Figura 12. Biodiversidad agrícola y paisaje en chinampas

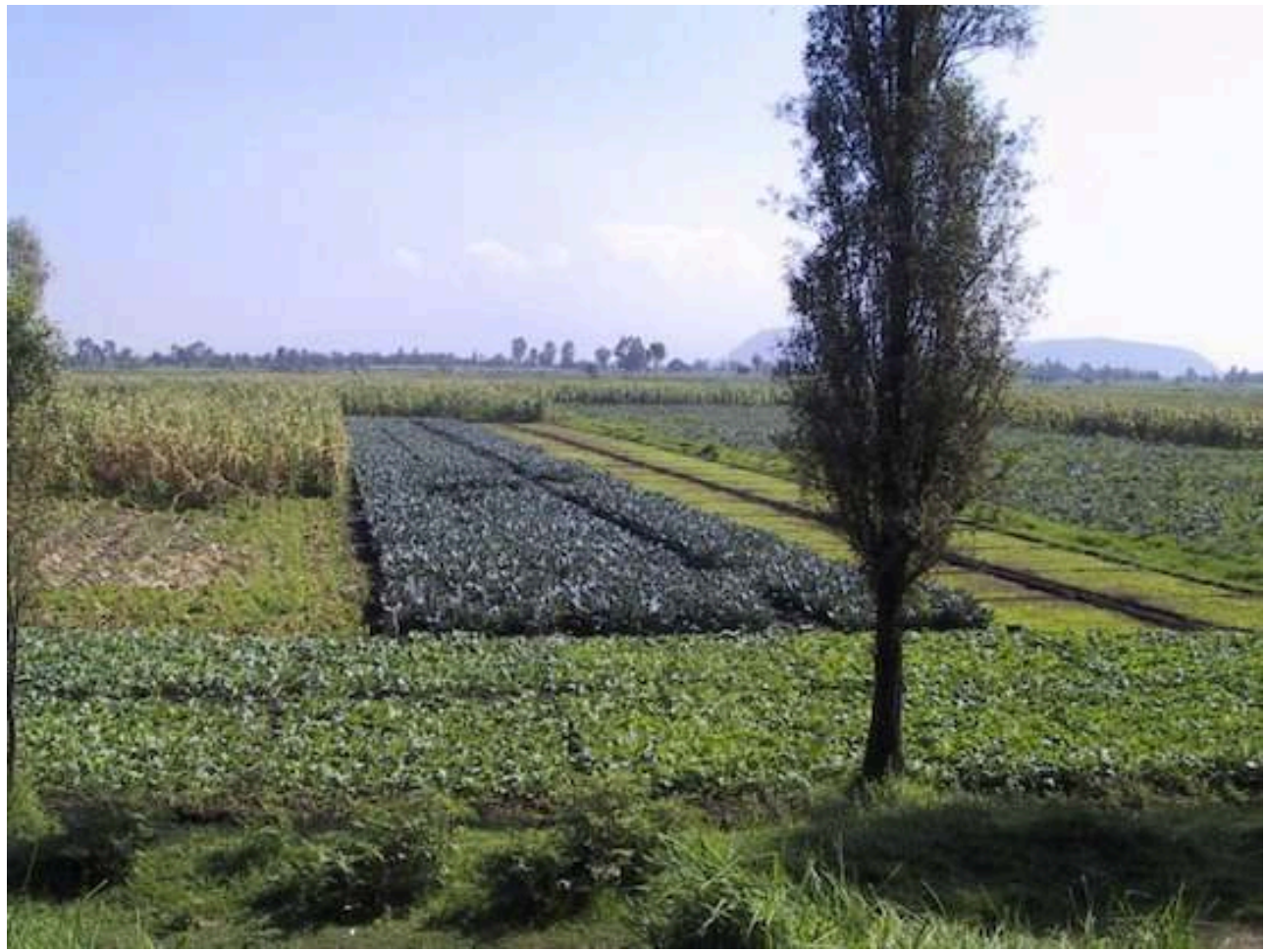

Fuente : Hermilio Navarro (2007).

La agricultura chinampera como recreación patrimonial colectiva es asociada a redes sociales tradicionales, íntimamente motivadas por festividades religiosas, con fines de solidaridad y apoyo mutuo (figura 13)

Figura 13. Festividad de muertos en Mixquic, poblado campesino ZMVM
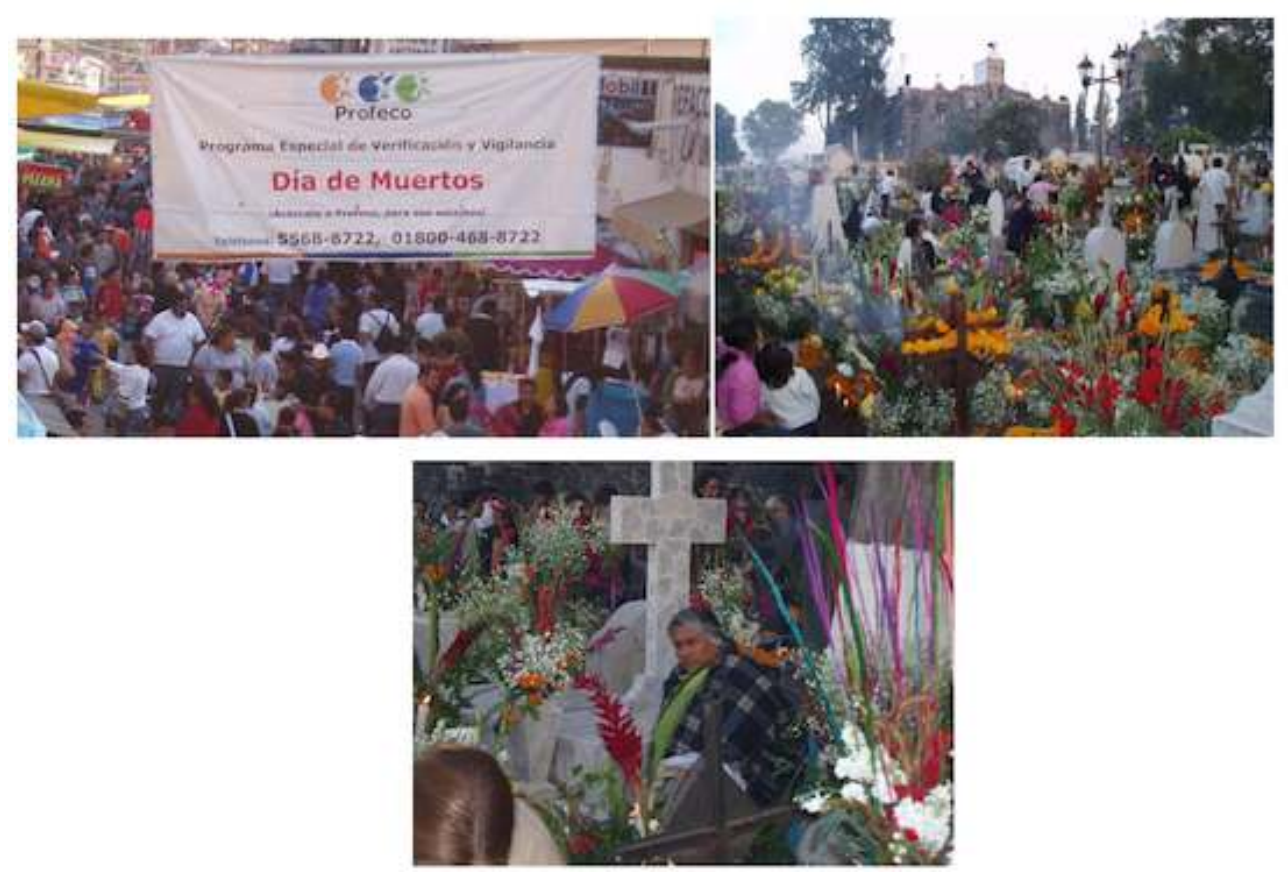


\section{Conclusión}

La urbanización ha generado conflictos internos entre los actores, en las escalas espaciales de expansión y de funcionamiento, así como disfuncionalidades entre la ciudad capital, los estados y municipios; por tanto se han generado un conjunto de circunstancias que han limitado un proyecto integral sostenible de desarrollo urbano.

Las numerosas imbricaciones de las escalas político-administrativas, en primer lugar la Federal y sus diversas secretarias de Estado, en segundo el de la ciudad de México y sus 16 Delegaciones, y en tercero del estado y sus 60 municipios políticamente autónomos ; por los limitados resultados logrados evidencian la existencia de un sistema territorial insuficientemente integrado, íntimamente asociado a un nivel de gobernanza ineficiente en la ZMVM.

Considerando las limitaciones de mecanismos eficaces de coordinación, así como el desinterés e incomprensión de la multifuncionalidad de la agricultura periurbana con fines de mitigar y contribuir a la solución de los problemas sociales y ambientales; en consecuencia es evidente la irresponsabilidad colectiva entre los principales actores, al favorecer el dejar-hacer y por tanto incidiendo cotidianamente en una profunda fragilización socio-ambiental, la cual limita la calidad de vida y compromete la capacidad de adaptación y viabilidad del sistema urbano-periurbano-rural.

\section{BIBLIOGRAFÍA}

Benítez, O., Estrella N. y Navarro H., "El papel de la agricultura en un espacio rural periurbano : Ocoyucan, Puebla”, Memoria Avances de Investigación, México Campus Puebla, 2004, 167 p.

Comisión Nacional del Agua., Sistema Cutzamala. Agua potable para millones de mexicanos, México, IDESA, 1994. $101 \mathrm{p}$.

Covarrubias F., Crecimiento Metropolitano de la ciudad de México y necesidades de financiamiento, México. Programa universitario sobre estudios de la ciudad-UNAM. 2000.

Demant, A., "Características del eje neo volcánico transmexicano y sus problemas de interpretación", Revista Geología, vol. 2, n 2, 1978, p. 72-187.

Instituto Nacional de Estadística, Geografía e Informática, Compendio de la población en México, México. INEGI, 2011.

Morales G., "La sobre-explotación apresura el exterminio de los manantiales en Tlaxcala", Foro El agua recurso vital no renovable, México, Excelsior, 2005.

Navarro H. y Pérez A., “Caracterización inorgánica del agua del río Texcoco, entre épocas del año y años”., Terra Latinoamericana, $\mathrm{n}^{\circ} 23,2005$, p. 183-190.

Navarro H, Agricultura campesina-indígena, patrimonio y desarrollo agroecológico territorial, Texcoco, México. Publicaciones Diamante, 2004. 214 p. 
Olivares, F., Agricultura campesina, cambio y permanencia : el caso de Mixquic, México, Universidad Iberoamericana, 2007, $304 \mathrm{p}$.

Rivera, R, Palacios, O., Chávez, J., Belmont, M., Nikolski, I., De la Isla, M., Guzmán, A., Terrazas, I. y Carrillo, R., "Contaminación por coliformes y helmintos en los ríos Texcoco, Chapingo y San Bernardino tributarios de la parte oriental de la cuenca del valle de México", Rev. Int. Contam. Ambient, $\mathrm{n}^{\circ} 23$ (2), 2007, p. 69-77.

Secretaría de Desarrollo Social, Consejo Nacional de Población e Instituto Nacional de Estadística, Geografía e Informática (SEDESOL-CONAPO-INEGI), Delimitación de las zonas metropolitanas de México en 2005, México, INEGI, 2007, 61 p.

Secretaría Medio Ambiente, Ciudad de México, “Asentamientos irregulares amenazan el suelo de conservación del Distrito Federal”, México, Milenio, 2011.

\section{NOTAS}

1. Zonas Metropolitanas Centrales: Valle de México, Puebla-Tlaxcala y Toluca.

2. Secretaria de Desarrollo Social - Comisión Nacional de Población-Instituto Nacional de Estadística y Geografía.

3. Germán Morales, diputado local y Presidente Com. Recursos Hidráulicos, Congreso estado Tlaxcala.

\section{RESÚMENES}

En México central se registró un fuerte crecimiento poblacional, caracterizado por insuficiencias de ordenamiento espacial, de oferta de servicios y para la calidad de vida, tales como: agua potable en calidad-cantidad, calidad ambiental, conservación de la calidad paisajística territorial, otros. Las dinámicas actuales evidencian imitaciones de gobernanza territorial y la emergencia de conflictos y riesgo de sustentabilidad urbana. La dinámica de la Zona Metropolitana Valle de México ilustra algunos conflictos emergentes con el proceso de urbanización: limitada coordinación de actores territoriales, desordenado crecimiento poblacional e impactos espaciales en territorios de expansión. Los cambios ocurridos por contribuyen para reflexionar sobre conflictos generados por las decisiones descoordinadas y omisas que incitan "una urbanización sin fin", que impide el funcionamiento y sobrevivencia de la diversidad de sistemas agrícolas, los cuales forman parte del patrimonio territorial. Además, la adaptación y en particular, la restringida viabilidad del sistema metropolitano generan riesgos e impactos sobre la sustentabilidad de los sistemas territoriales vecinos.

Les modalités de la croissance urbaine dans le centre de Mexico montrent une forte expansion de la population et se caractérisent par des insuffisances de l'aménagement spatial, des offres de services, des qualités environnementales et des cadres de vie. Au rang de celles-ci figurent les carences d'eau - carences qualitatives et quantitatives - la conservation des qualités paysagères des territoires. Par ailleurs, les dynamiques montrent les limites de la gouvernance territoriale en cours et produisent ainsi l'émergence de conflits, et le risque de la durabilité urbaine. La 
dynamique de la zone métropolitaine de la vallée de Mexico illustre l'apparition de certains conflits avec le processus d'urbanisation, parmi lesquels la coordination insuffisante entre les acteurs, l'accroissement désordonné de la population et leurs impacts sur ces territoires en expansion. Les changements poussent à réfléchir sur des conflits produits par des choix non planifiés qui, dessinant "une urbanisation interminable ", empêchent le fonctionnement et la survivance d'une diversité de systèmes agricoles, lesquels font partie du patrimoine territorial. Enfin, ce système métropolitain de développement met en péril la durabilité des systèmes territoriaux voisins.

In the Center of Mexico show a strong population growth, characterized by insufficient spatial ordering, supply of services and life quality, such as drinking water in quality and quantity, environmental quality, conservation of the territorial landscape quality, among others. In addition, the current dynamics reveal the limitations of territorial governance and thus allow the emergence of conflicts and risk of urban sustainability. The analysis of the metropolitan area of the Valley of Mexico illustrates some features and emerging conflicts in the process of urbanization, including inordinate population growth and spatial impacts on expansion territories. That contribute to reflect on conflicts generated by centralized processes of "urbanization without order" which hinders the functioning of the patrimonial inheritance and domestic agricultural as well as neighboring territorial systems.

\section{ÍNDICE}

Mots-clés: métropoles, échelles, urbanisation interminable, dégradation, conflits

Keywords: metropolis, scales, urban sprawl, degradation, conflicts

Palavras-chave: metrópolis, escalas, urbanización descontrolada, degradación, conflicto

\section{AUTORES}

\section{HERMILIO NAVARRO}

Professeur, Centre d'études pour le développement rural, Collège d'études doctorales en sciences agricoles, Mexico.

hermnava[at]colpos[dot]mx et hermnava[at]gmail[dot]com

\section{MA ANTONIA PÉREZ}

Chargée de recherche, Centre d'études pour le développement rural, Collège d'études doctorales en sciences agricoles, Mexico.

molvera[at]colpos[dot]mx

\section{DIEGO FLORES}

Chercheur associé, Centre d'études en agroécologie, Collège d'études doctorales en sciences agricoles, Mexico.

dfs[at]colpos.mx 